This item was submitted to Loughborough's Research Repository by the author.

Items in Figshare are protected by copyright, with all rights reserved, unless otherwise indicated.

\title{
Characterization of CdTe photovoltaic devices passivated using hydrogen plasma
}

PLEASE CITE THE PUBLISHED VERSION

https://doi.org/10.1109/PVSC.2017.8366464

PUBLISHER

IEEE

VERSION

AM (Accepted Manuscript)

LICENCE

CC BY-NC-ND 4.0

\section{REPOSITORY RECORD}

Munshi, Amit, Piotr M. Kaminski, Ali Abbas, Shiva T. Reddy, Sreeram Chandralal, Michael Walls, and Walajabad S. Sampath. 2019. "Characterization of Cdte Photovoltaic Devices Passivated Using Hydrogen Plasma”. figshare. https://hdl.handle.net/2134/27444. 


\title{
Characterization of CdTe Photovoltaic Devices Passivated Using Hydrogen Plasma
}

\author{
Amit Munshi ${ }^{1}$, Piotr Kaminski ${ }^{2}$, Ali Abbas ${ }^{2}$, Shiva Tarun Reddy ${ }^{1,3}$, Sreeram Chandralal ${ }^{1,4}$, John Walls ${ }^{2}$, \\ Walajabad Sampath ${ }^{1}$ \\ ${ }^{1}$ NGPV (Next Generation PV Center), Department of Mechanical Engineering, Colorado State University, \\ Fort Collins, CO 80523, United States \\ ${ }^{2}$ CREST (Centre for Renewable Energy Systems Technology), Loughborough University, Leicestershire, \\ LE11 3TU, United Kingdom \\ ${ }^{3}$ Department of Electronics and Communication Engineering, Amrita University, Amritapuri, Kerala- \\ 690525, India \\ ${ }^{4}$ Department of Mechanical Engineering, Amrita University, Amritapuri, Kerala-690525, India
}

\begin{abstract}
Thin-film polycrystalline CdTe photovoltaic devices were studied using electrical and material characterization methods to understand the effects of hydrogen plasma passivation treatment. Devices were fabricated using sublimation and were exposed to hydrogen plasma for 10, 20 and 30 minutes. Current density vs voltage measurements were performed to measure the performance of the devices. Capacitance vs voltage graphs showed that dopants are active and the device behaved like a $\mathrm{CdCl}_{2}$ passivated device. Microscopic characterization was performed using SEM and (S)TEM that showed larger grains and more homogenous film coverage as compared to films without passivation suggesting grain growth during $\mathrm{H}_{2}$ passivation.
\end{abstract}

\section{INTRODUCTION}

Hydrogen plasma passivation has been extensively studied for semiconductor materials such as GaAs, AlGaAs and amorphous as well as crystalline silicon. It is understood to cause surface modification in GaAs[1] wafers and passivation of deep level defects in molecular beam epitaxial (MBE) GaAs[2]. Hydrogen passivation is also used to passivate point defects such as dangling bonds in crystalline silicon[3] and improve passivation of interface between amorphous and crystalline silicon[4].

These studies suggest that hydrogen introduction using plasma passivation process has a significant impact on semiconductor properties. Some studies have also been performed to understand shallow donor neutralization in $n$-type indium doped CdTe[5]. Photoluminescence characterization of $p$-type undoped CdTe shows hydrogen introduction within CdTe film suggesting hydrogen actively plays a role in passivation of defects in CdTe as in case of other semi-conductor materials[6]. Since CdTe is now a prominent photovoltaic technology and forms a considerable portion of commercial photovoltaic installations, it is important to understand the effect of hydrogen plasma passivation on CdTe photovoltaic devices. CdTe is one of the most economical and commercially viable photovoltaic technologies and further improvement in efficiency would pave way for reduction in manufacturing cost of CdTe photovoltaic modules.

In this study, CdS/CdTe photovoltaic devices were fabricated sublimation of CdS and CdTe. Hydrogen plasma was generated in-situ without break of vacuum after CdTe deposition. Device performance and efficiency were measured for devices that were passivated using hydrogen plasma and compared against devices fabricated without passivation. SEM and (S)TEM images of the film surface and film cross-section were collected respectively to understand the effect of hydrogen plasma exposure on grain structure. EDS maps were not collected since EDS would not be able to detect presence of hydrogen. Capacitance vs voltage and capacitance vs frequency measurements were performed to understand the effects of exposure to hydrogen plasma on electrical behavior of the device.

\section{FABRICATION AND CHARACTERIZATION METHODS}

The CdS and CdTe thin films were deposited on NSG TEC 10 soda lime glass that was coated with fluorine-doped tin oxide (FTO), a transparent conducting oxide (TCO). Deposition of these films was performed in a continuous inline sublimation tool optimized at Colorado State University for fabrication of thin-film CdTe photovoltaic devices. The load-lock section of the sublimation tool had a protruding plasma source that was used to expose the films to hydrogen plasma after deposition of CdTe films. Thickness of CdS film was $\sim 130 \mathrm{~nm}$ while CdTe absorber layer thickness was measured to be $\sim 2.4 \mu \mathrm{m}$. Flow of hydrogen gas was controlled using a mechanical valve and the pressure in the plasma source was maintained at 800 mTorr. The electrical parameters used to ignite hydrogen plasma were controlled using a Glassman High Voltage power controller and the parameters were maintained at $15 \mathrm{~mA}$ current and $450 \mathrm{~V}$ voltage. The films were exposed to plasma for 10 and 25 minutes for different substrates. 
Thereafter, the films were heated to $\sim 140^{\circ} \mathrm{C}$ and $\mathrm{CuCl}$ was deposited on the film surface for 110 seconds. This was followed by 220 seconds of annealing at $220^{\circ} \mathrm{C}$. This process step was performed to form a $\mathrm{Cu}$ back contact. Carbon and nickel paint in polymer binder where then sprayed on these films to form the back electrode. Figure 1 shows the schematic of this device structure. The cells were then delineated using a mask and bead blasting to fabricate 25 small scale devices on the substrate. The devices had an area of $\sim 0.65 \mathrm{~cm}^{2}$.

For electrical characterization, open-circuit voltage $\left[\mathrm{V}_{\mathrm{OC}}\right]$, short-circuit current $\left[\mathrm{J}_{\mathrm{SC}}\right]$, fill-factor and percentage efficiency data were collected using $\mathrm{J}-\mathrm{V}$ measurements.

In-depth microstructure characterization of the CdTe film was carried out using Transmission Electron Microscopy (TEM) and High Resolution Transmission Electron Microscopy (HRTEM). TEM samples were prepared using Focused Ion Beam (FIB) milling using dual beam FEI Nova 600 Nanolab. A standard in-situ lift out method was used to prepare the cross-section sample through the film stack into the glass substrate. A platinum overlay was deposited on the top of the film to define the area of interest on surface of the sample, homogenize the final thinning of the samples and to avoid damage to the CdTe film surface from the ion beam. STEM bright-field images and high resolution TEM images were collected using a FEI Tecnai F20 (S)TEM operating at $200 \mathrm{kV}$.

Capacitance-Voltage characteristics were obtained using Kyesight E4990A Impedance Analyzer. The sample bias was swept from $-2 \mathrm{~V}$ to $1 \mathrm{~V}$ at $20 \mathrm{mV}$ step, the capacitance measurements were taken using $500 \mathrm{kHz}$ frequency.

\section{ELECTRICAL CHARACTERIZATION}

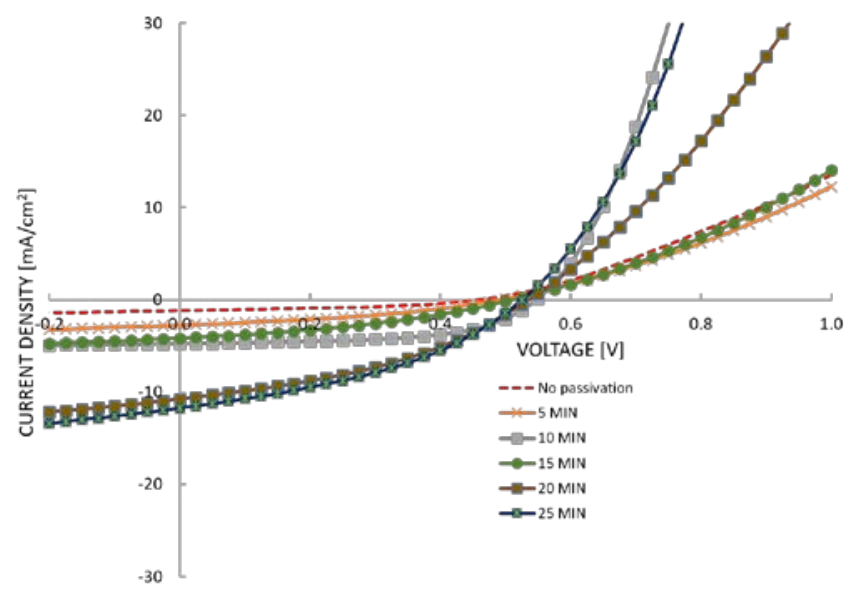

Fig. 1. J-V measurement of CdS/CdTe devices with varying hydrogen plasma exposure time

As can be observed from current density vs voltage measurements (figure 1), as the films are exposed to hydrogen plasma for longer periods of time there an improvement in short-circuit current. However, best fill-factor of $58.2 \%$ and open-circuit voltage of $549 \mathrm{mV}$ is seen for 10 minutes of passivation time. Longer passivation time for these films show reduction in fill-factor as well as open-circuit voltage. This may be caused by surface damage induced by long exposure to hydrogen plasma leading. Damage to CdTe surface at long passivation times requires to be verified using SEM.

As deposited CdS/CdTe hetero structures not activated using $\mathrm{CdCl}_{2}$ did not provide response. When the material was

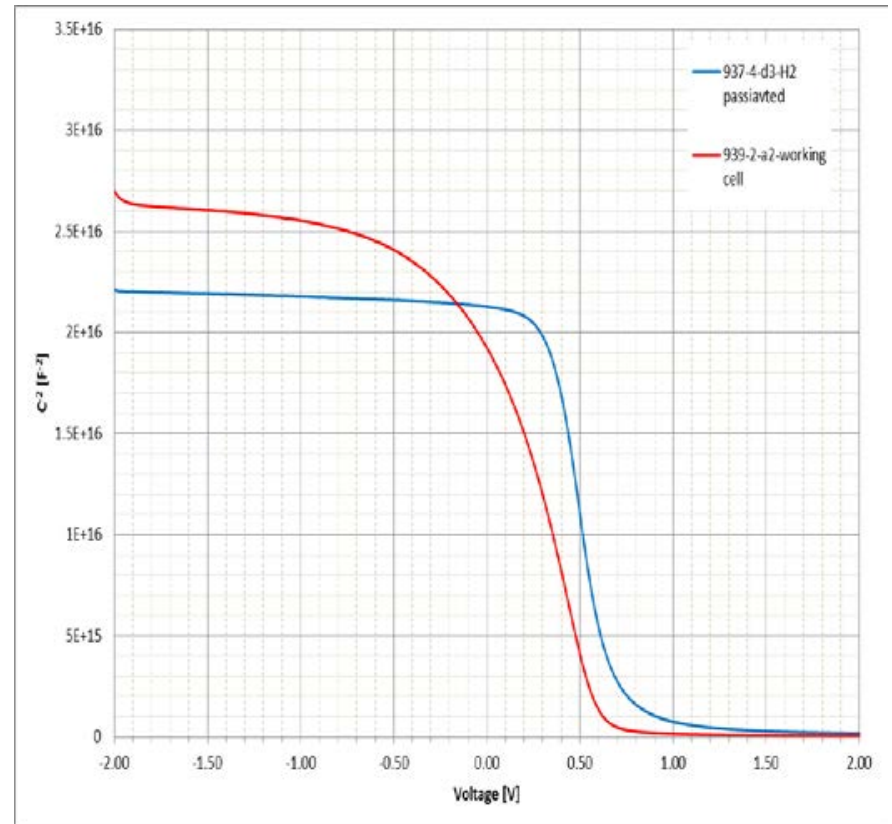

Fig. 2. Mott-Schotkky characteristics of devices with and without hydrogen plasma passivation

$\mathrm{H}_{2}$ passivated the $\mathrm{C}-\mathrm{V}$ response showed characteristics typical for a working solar cell. Mott-Schotkky characteristics of reference cell and $\mathrm{H}_{2}$ passivated CdTe are shown in figure 2 . The $\mathrm{V}_{\text {bi }}$ of $\mathrm{H}_{2}$ passivated material was higher $(\sim 0.67 \mathrm{~V})$ than for working solar cell $(\sim 0.62 \mathrm{~V})$.

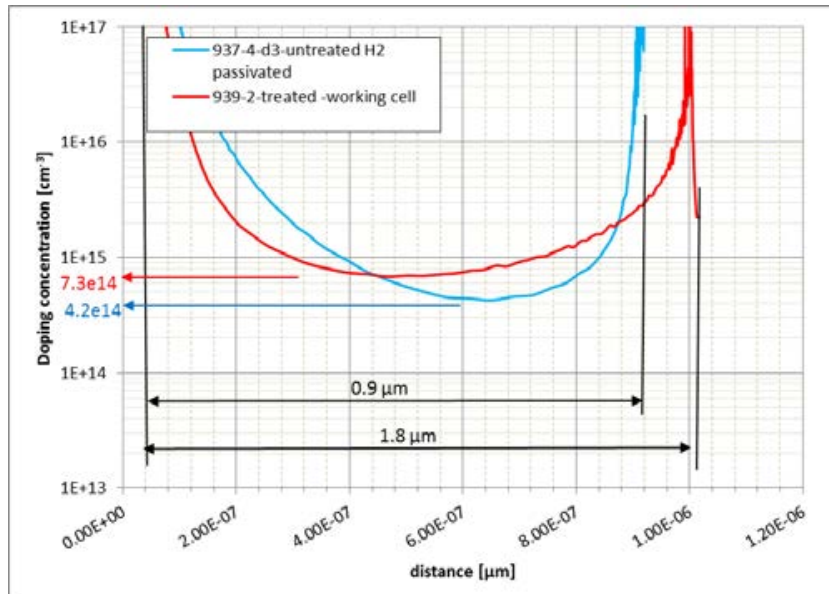

Fig. 3. Doping profiles extracted from Mott-Schottky characteristics for a device with and without hydrogen plasma passivation 
Doping profiles were extracted from the $\mathrm{C}-\mathrm{V}$ curves. The $\mathrm{H}_{2}$ treated device showed $\sim 4.210^{14} \mathrm{~cm}^{-3}$, the working cell showed $\sim 7.310^{14} \mathrm{~cm}^{-3}$. Calculated doping profiles are plotted in figure 3.

\section{MATERIALS CHARACTERIZATION}

Scanning electron microscopy (SEM) was used to study the surface of CdTe films after exposure to hydrogen plasma passivation while scanning transmission electron microscopy (STEM) was performed to study the cross-section of these CdS devices. SEM images of the surface showed a more homogenous coverage of CdTe grains with minimal voids after hydrogen plasma passivation (figure 4). These features were similar to the films that are passivated using $\mathrm{CdCl}_{2}$ on similar films.

STEM cross-section images (figure 5) showed stacking faults present in CdTe grains. The grains appeared to small near the interface of CdS and CdTe. These are typical features observed in CdTe grains not passivated using $\mathrm{CdCl}_{2}$. The grain boundaries appeared to be distinct and there were no voids visible in the film. The growth of CdTe was also
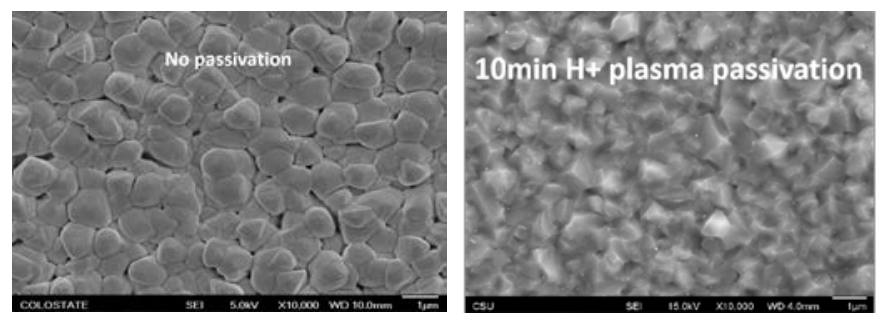

Fig. 4. Surface SEM image of as deposited CdTe film (left) and film surface after exposure to hydrogen plasma for 10 minutes

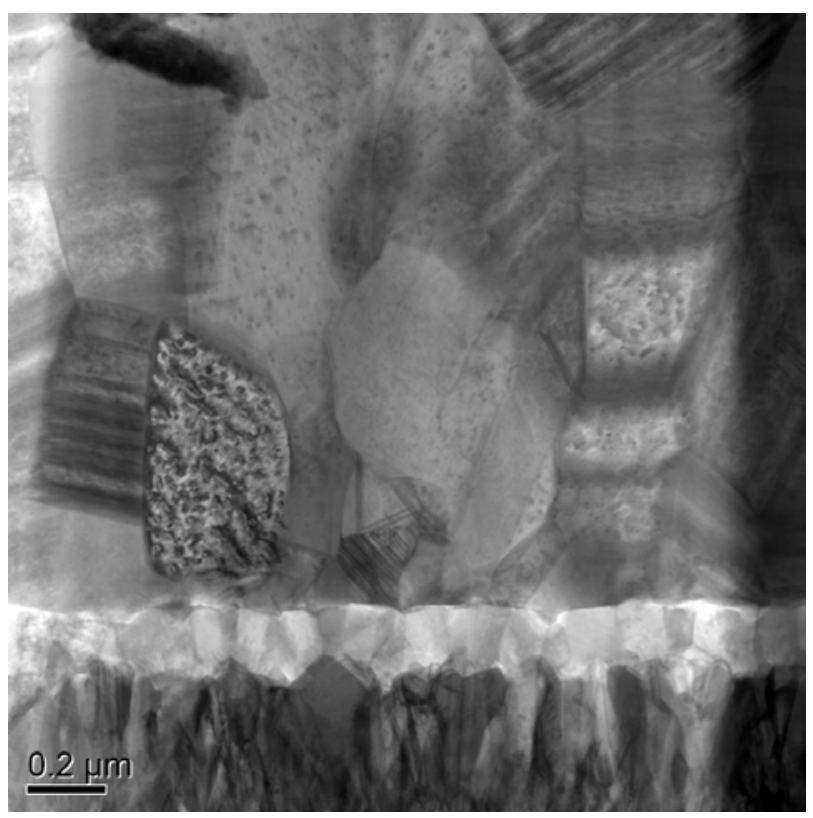

Fig. 5. Cross-section STEM image of CdS/CdTe film after 10 minutes of exposure to hydrogen passivation conformal on CdS. There were no visible signs of material diffusion and the CdS/CdTe interface also appeared to be distinct and abrupt.

\section{CONCLUSIONS}

Current density vs voltage measurements show that hydrogen passivation has a positive effect on CdS/CdTe device performance. C-F and C-V measurements also suggest that these devices have characteristics of working devices. However, cross-section electron image shows presence of stacking faults that persists post hydrogen plasma passivation treatment. This suggests hydrogen plasma exposure may be responsible for affecting other point defects such as dangling bonds as well as may be passivating the surface that results in improvement of device performance.

\section{ACKNOWLEDGEMENTS}

The CSU authors thank support from NSF's Accelerating Innovation Research, DOE's SunShot and NSF's Industry/University Cooperative Research Center programs. The Loughborough authors are grateful to EPSRC for funding through the Supergen SuperSolar Hub.

\section{REFERENCES}

[1] E. Yoon, R. A. Gottscho, V. M. Donnelly, and H. S. Luftman, "GaAs surface modification by room-temperature hydrogen plasma passivation,” Appl. Phys. Lett., vol. 60, no. 21, pp. 2681-2683, 1992.

[2] W. C. Dautremont-Smith, J. C. Nabity, V. Swaminathan, M. Stavola, J. Chevallier, C. W. Tu, and S. J. Pearton,

"Passivation of deep level defects in molecular beam epitaxial GaAs by hydrogen plasma exposure,” Appl. Phys. Lett., vol. 49, no. 17, pp. 1098-1100, 1986.

[3] J. L. Benton, C. J. Doherty, S. D. Ferris, D. L. Flamm, L. C. Kimerling, and H. J. Leamy, "Hydrogen passivation of point defects in silicon,” Appl. Phys. Lett., vol. 36, no. 8, pp. 670671, 1980.

[4] A. Descoeudres, L. Barraud, S. De Wolf, B. Strahm, D. Lachenal, C. Guérin, Z. C. Holman, F. Zicarelli, B. Demaurex, J. Seif, J. Holovsky, and C. Ballif, “Improved amorphous/crystalline silicon interface passivation by hydrogen plasma treatment," Appl. Phys. Lett., vol. 99, no. 12, pp. 1-4, 2011.

[5] S. Gurumurthy, H. L. Bhat, B. Sundersheshu, R. K. Bagai, and V. Kumar, "Shallow donor neutralization in CdTe:In by atomic hydrogen,” Appl. Phys. Lett., vol. 2424, p. 2424, 1995.

[6] J. Hamann, D. Blass, C. Casimir, T. Filz, V. Ostheimer, C. Schmitz, H. Wolf, T. Wichert, A. Burchard, M. Deicher, and R. Magerle, "Hydrogen-related photoluminescence in CdTe,” Appl. Phys. Lett., vol. 72, no. 5, pp. 554-556, 1998. 
